\title{
Alfabeta: Uma proposta de objeto de aprendizagem para apoio a alfabetização
}

\author{
Lívia de Sousa Barreto ${ }^{1}$, Isabela Nascimento Cavaco ${ }^{1}$, Danielle Rousy Dias da \\ Silva ${ }^{1}$ \\ ${ }^{1}$ Centro de Informática (CI) - Universidade Federal da Paraíba (UFPB) \\ João Pessoa, PB - Brasil \\ \{livia93.sousa, isabela.nascimento, danielle.rousy\}@gmail.com
}

\begin{abstract}
This article describes a proposal and development of a learning object, in the form of an application, aimed at the playful teaching of children in the literacy phase, so that they can take advantage of the technology and exercise their knowledge in an interactive and fun way. In the process of development of this tool, the characteristics of the users were studied and an analysis of applications dealing with the same theme using an instrument of evaluation of educational software was performed. Bibliographical studies were also carried out to understand the methodologies of teaching and the literacy process, and review of activities extracted from teaching materials used by teachers in the classroom.
\end{abstract}

Resumo. Este artigo descreve uma proposta e desenvolvimento de um objeto de aprendizagem, em forma de aplicativo, voltado para o ensino lúdico de crianças em fase de alfabetização, para que possam aproveitar da tecnologia e exercitar seus conhecimentos de forma interativa e divertida. No processo de desenvolvimento desta ferramenta, foram estudadas as características dos usuários e realizado uma análise de aplicativos que tratam do mesmo tema utilizando um instrumento de avaliação de softwares educacionais. Também foram realizados estudos bibliográficos para compreender as metodologias de ensino e o processo de alfabetização, e revisão de atividades extraídas de materiais pedagógicos utilizados por professores em sala de aula.

\section{Introdução}

Vivemos na era da informação, uma vez que a obtenção e o compartilhamento de informações está cada vez mais rápido e acessível em razão da internet, e de instrumentos tecnológicos constantemente aprimorados, como é o caso dos computadores, celulares, tablets e televisores. A expansão da tecnologia na educação, de acordo com Costa e outros (2015), tem feito com que novos cenários de aprendizagem surjam na sociedade contemporânea, tais quais os jogos educativos, que possuem possibilidades didático-pedagógicas pertinentes para o desenvolvimento de aprendizagens significativas, especialmente pela popularidade em meio aos estudantes e o poder de sedução que desempenham sobre eles.

Diante disso, este trabalho propõe o desenvolvimento de um produto intitulado Alfabeta, produzido para smartphones e tablets, e dirigido, em princípio, ao público das 
crianças em processo de alfabetização, entre 6 e 9 anos, de forma a possibilitar-lhes um aprendizado mais dinâmico e interativo. Como afirmado por Santos (2016), o uso da informática na educação estimula o desenvolvimento da autonomia, da curiosidade e da criatividade, promovendo a construção do conhecimento da criança. Portanto, a proposta deste produto é sua utilização como ferramenta lúdica de apoio e de motivação para o aprendizado informal, sem necessariamente ocorrer dentro da sala de aula ou com acompanhamento de um professor. Como citado por Vercelli (2014), aprende-se em qualquer situação e de maneiras diferenciadas, em espaços formais e não formais, como na internet, celular, tablet, livro, cinema, teatro, museu e em tantos outros espaços.

Este artigo está organizado da seguinte forma: a próxima seção apresenta a fundamentação pedagógica e o processo de seleção de aplicativos similares. A seção 3 introduz o formulário de avaliação de software educacional e os resultados obtidos. A seção 4 apresenta o protótipo do aplicativo. A seção 5 descreve o processo de desenvolvimento e, por fim, a seção 6 expõe as considerações finais e trabalhos futuros.

\section{Fundamentação}

Para implementar um aplicativo como objeto de aprendizagem, o primeiro passo consistiu na elaboração de protótipos iniciais, baseados nas atividades encontradas nos testes de aplicativos, descritos mais adiante, e na apresentação destes à duas especialistas na área educacional. Após esta fase, foram colhidas suas considerações e introduzidas as metodologias de aprendizagem, que podem ser abordadas de forma instrucionista, como é feito nos aplicativos encontrados sobre o tema, e de forma construtivista, que é a maneira mais atualizada de ensinar o tema em algumas escolas. Matsunaga e outros (2013) afirmam que ferramentas instrucionistas possuem, tipicamente, perguntas com respostas "certas" e "erradas", com pontos ou benefícios associados a tais escolhas, entre outras características. É importante ressaltar que uma metodologia não se pode dizer melhor do que a outra, pois assim como afirma Norman e Spohrer (1996), "estudantes e conteúdos diferem entre si, requerendo diferentes abordagens desde as mais tradicionais às mais modernas.

\subsection{Pesquisa com aplicativos similares}

Foram selecionados aplicativos existentes no mercado com o mesmo objetivo proposto anteriormente, a fim de estudar a viabilidade da construção de uma nova ferramenta mais efetiva, e de obter parâmetros para elencar os requisitos do novo objeto de aprendizagem, através de uma avaliação de cada aplicativo. Os aplicativos foram encontrados na plataforma do Google ${ }^{1}$, por meio dos termos "ABC", "Alfabetização" e "Sílabas", e consistem ao todo em 15 aplicativos, por terem idioma em português ou inglês, 4 ou mais estrelas de avaliação e pelo menos 100 avaliações de usuários.

1 https://play.google.com/store/apps?hl=pt_BR 
VI Congresso Brasileiro de Informática na Educação (CBIE 2017)

Anais dos Workshops do VI Congresso Brasileiro de Informática na Educação (WCBIE 2017)

\section{Formulário de Thomas Reeves}

Os aplicativos e suas funcionalidades foram avaliados utilizando o formulário de avaliação de softwares educacionais proposto por Thomas Reeves ${ }^{2}$, em que ele definiu 10 critérios para avaliação de interface, e 14 para avaliação pedagógica. O formulário utilizado foi colocado na ferramenta do Google Forms ${ }^{3}$ através de um endereço ${ }^{4}$. O formulário original está disponível na página online do pesquisador, mas por questão de espaço, a definição deste está disponível apenas no formulário online.

\subsection{Resultados da Avaliação dos Aplicativos Selecionados}

Dos resultados da avaliação, o gráfico abaixo indica os critérios que foram implementados adequadamente pela minoria, ou seja, aqueles que faltaram na maioria dos aplicativos:

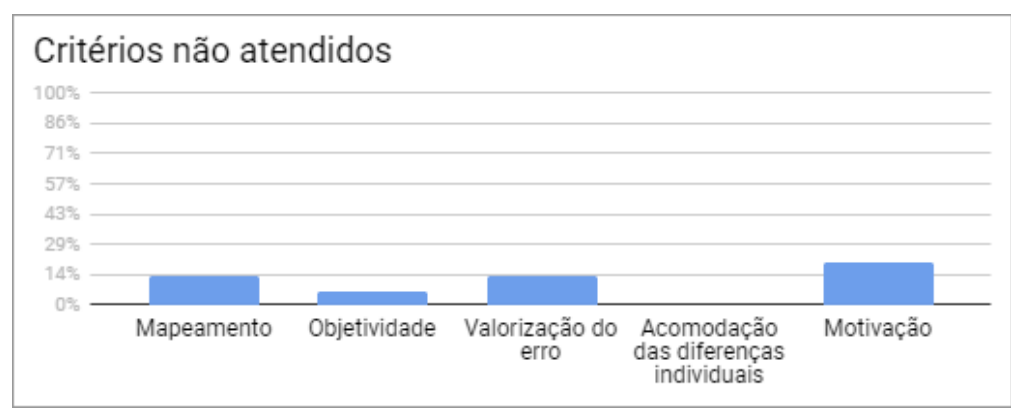

Gráfico 1: Critérios que não foram atendidos na avaliação.

Fonte: Elaborado pelas autoras.

No gráfico 1 acima, destacam-se os critérios "valorização do erro" e "motivação", por estes serem os mais importantes na implementação. O primeiro permite ao aluno aprender com a experiência, e não com a ausência de erro, e o segundo incentiva-o a continuar persistindo nas atividades. Apenas $20 \%$ dos aplicativos utilizam elementos como pontuação, cartões colecionáveis, figurinhas, pontuação com estrelas, entre outros. Esses elementos, conforme descrito por Cavaco (2016), fazem parte do conceito de gamificação e servem para recompensar o usuário por completarem alguma ação, mantendo-o engajado e motivado a continuar jogando, o que é especialmente importante em ambientes voltados para aprendizagem.

Com as informações obtidas diante desta avaliação, buscamos incluir nos requisitos do produto proposto a satisfatoriedade dos critérios que deixaram de ser atendidos adequadamente, na medida do possível. Este estudo teve, ainda, uma importância que foi além da definição de requisitos, sendo fundamental para compreender as bases de um aplicativo educacional, que precisa atender não só a critérios de interface, mas também a critérios pedagógicos. Os resultados completos e a

\footnotetext{
2 Professor emérito em Aprendizagem, Design e Tecnologia pela Universidade de Georgia, EUA. Página pessoal disponível em: < http://treeves.coe.uga.edu/edit8350/UIRF.html>. https://www.google.com/intl/pt-BR/forms/about/

Disponível em: $<$ https://goo.gl/forms/VhdhlbKGWFShlz132>. Acesso em: 11 de abril de 2017.
} 
VI Congresso Brasileiro de Informática na Educação (CBIE 2017)

Anais dos Workshops do VI Congresso Brasileiro de Informática na Educação (WCBIE 2017)

relação de aplicativos selecionados foram disponibilizados em uma planilha através do endereço ${ }^{5}$ descrito no rodapé.

\section{Apresentação do Software}

A figura 2 mostra o menu de atividades, no qual cada atividade deverá ter alguma descrição ou imagem referente ao tipo de conteúdo trabalhado pela mesma. A figura 4 ilustra a primeira atividade, que trabalha a ordem do alfabeto. Alguns ajustes ainda precisam ser feitos na implementação para que as letras do lado direito fiquem mais espalhadas e bagunçadas, com uma cor diferente para destacar o objetivo da fase. No exemplo da figura 2, a atividade trabalha com a ordem do alfabeto. Descrições em áudio devem ser trabalhadas em cada atividade para que usuários que não dominem a leitura também sejam capazes de conclui-las.
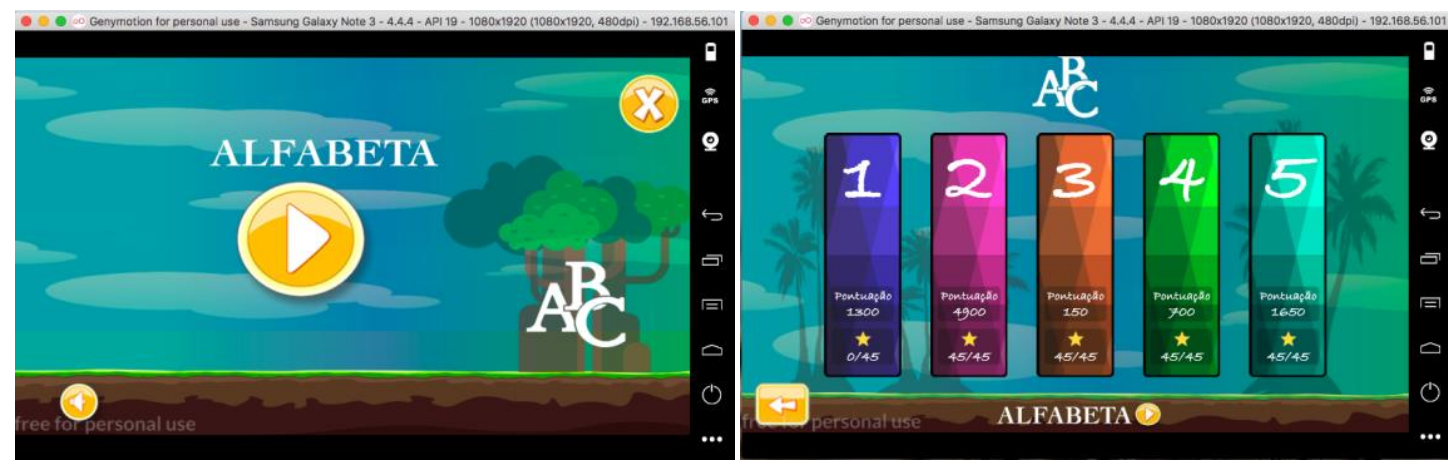

Figuras 1 e 2: Tela Inicial do aplicativo AlfaBeta e Tela com as atividades, respectivamente.

Fonte: Elaborado pelas autoras.
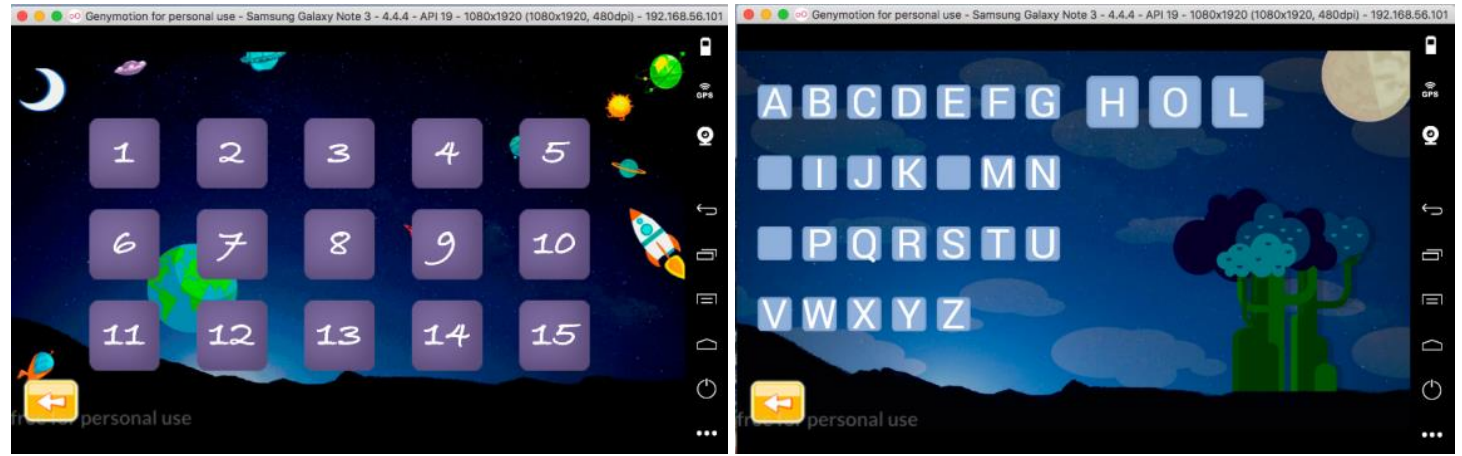

Figuras 3 e 4: Tela com os níveis da atividade 1 do aplicativo AlfaBeta e Tela da atividade do nível 1, respectivamente.

Fonte: Elaborado pelas autoras.

Com relação aos critérios destacados na avaliação, "mapeamento" está sendo implementado como "poderoso", pois permite visualizar as atividades que existem/faltam e as que já foram completadas. O critério "acomodação a diferenças individuais" será atendido na medida em que as atividades implementem também

${ }^{5}$ https://docs.google.com/spreadsheets/d/1XqgHHZIbZ5s9zM5w0uiQgBmsShtjtG2_jM0JRmzETH4/edit? usp=shari 
VI Congresso Brasileiro de Informática na Educação (CBIE 2017)

Anais dos Workshops do VI Congresso Brasileiro de Informática na Educação (WCBIE 2017)

descrições auditivas das atividades, para os usuários que não dominam completamente a leitura.

As atividades foram planejadas para o aplicativo AlfaBeta com auxílio de materiais de apoio pedagógico utilizados por professores em sala de aula.

O aplicativo está em fase de protótipo até o momento, com apenas a primeira atividade implementada, devido à limitação da equipe, composta apenas pelas alunas Lívia Barreto e Isabela Cavaco, supervisionado pela professora Dr. Danielle Rousy.

\section{Considerações Finais e Trabalhos Futuros}

Buscamos como diferencial atender aos critérios que deixaram a desejar em outros aplicativos, sendo eles: mapeamento, valorização do erro, acomodação de diferenças individuais, objetividade e motivação. Também é importante destacar que o aplicativo não pretende se monetizar por meio de publicidades, por não serem apropriadas para $o$ público alvo definido.

Por se encontrar em fase de protótipo, ainda serão necessários alguns ajustes antes que possamos avaliar o aplicativo com alguns usuários finais, bem como validar através do formulário de Reeves como foi feito com os outros aplicativos, a fim de atestar metodologicamente a eficiência dos critérios não atendidos. Além das avaliações, deseja-se também compreender nos trabalhos futuros a possibilidade de permitir que a aplicação seja editada por um professor, para que o mesmo possa adicionar e personalizar uma atividade, adicionando novas possibilidades de aprendizado para os alunos.

\section{Referências}

Cavaco, I. N. (2016) "Gamificação aplicada no ensino: Identificando boas práticas através de um mapeamento sistemático”, p.22-25.

Costa, P. B. N.; Barbosa, E. S.; Sartore, A.R. (2015) "Interatividade em Jogos Educativos online no âmbito das TICs e suas implicações nos processos educacionais da sociedade contemporânea" In: XXX Congresso Latino Americano de Sociologia Alas, San Jose, v. 1. p. 1-20.

Matsunaga, R. M.; Bispo, D. M.; Borges, M. A. (2013) "Processo de construção de jogos para aprendizado", Jornada de Atualização em Informática na Educação, v. 1, n. 1 .

Norman, D. A., Spohrer, J. C. (1996) "Learner-centered education", Communications of the ACM, v.39, n.4, p.24-27.

Santos, R. et al. (2016) "Meu ABC: uma aplicação multimédia para alfabetização contextualizada", In: Anais dos Workshops do Congresso Brasileiro de Informática na Educação, p. 304.

Vercelli, L. C.; Melo, S. (2014) "O uso das tecnologias de informação e comunicação na educação infantil: um estudo de caso", In: Gestão, Programa de Mestrado. 